\title{
A IDEOLOGIA DE GÊNERO NA PUBLICIDADE CONTEMPORÂNEA
}

\section{Débora Mendes ${ }^{1}$}

\begin{abstract}
Resumo
Ao estudar a publicidade contemporânea, reconhece-se a necessidade de conciliar a perspectiva clássica - dos estudos macrossociológicos - com as teorias pósmodernas (que abordam a subjetividade e a identidade). Essa compatibilização se verifica também nos estudos feministas, representados nesse artigo por Lauretis (1994) e Hollanda (1994). Na tentativa de entender essa necessária conciliação, o texto começa traçando um breve esboço acerca da dominação e do poder, para, em seguida, buscar demonstrar como as teóricas feministas, an relacionarem tais correntes, contribuíram para o desenvolvimento da teoria social. Tal aproximação se verifica, por exemplo, no conceito ideologia de gênero, que traz a ideia de formação das subjetividades e das identidades nos e pelos processos sociais abarcando, simultaneamente, os processos estruturais que atuam na produção publicitária e reforçam o padrão androcêntrico.
\end{abstract}

Palavras-chave: Publicidade. Estudos feministas. Ideologia. Subjetividade.

\section{GENDER IDEOLOGY IN CONTEMPORARY ADVERTISING}

\section{Abstract}

In studying contemporary advertising, we recognize the need for reconciling the classic perspective - of macro-sociological studies - with postmodern theories

\footnotetext{
1 Mestranda em Sociologia pela Universidade Federal de São Carlos. End. eletrônico: deboramendes23@gmail.com
} 
(which deal with subjectivity and identity). This conciliation can also be noted in feminist studies, represented in this article by Lauretis and Hollanda (1994). In order to understand this necessary conciliation, the text begins with a brief sketch about domination and power and then it tries to demonstrate how feminist theorists, when they relate those approaches, have contributed to the development of social theory. This can be seen, for instance, in the gender ideology concept, which brings the idea of the formation of subjectivities and of identities in and through social processes and comprehends simultaneously the structural processes which act in the advertising production and reinforce the androcentric standard.

Keywords: Advertising. Feminist studies. Ideology. Subjectivity.

\section{INTRODUÇÃ̃O}

0 interesse pelo estudo sobre os usos da imagem feminina na publicidade contemporânea nasceu ainda na graduação, em razão do incômodo que as campanhas comerciais de cerveja me suscitavam. Como consumidora do produto não me identificava com as mensagens veiculadas, pelo contrário, sentia uma certa repulsa com a tão propagada analogia entre mulher e cerveja, manifestada em frases do tipo: "Me dá uma loira gelada!"

Nessa etapa, o foco do trabalho era o produtor. Iniciamos a pesquisa com a identificação da agência publicitária responsável pela produção das campanhas comerciais da cervejariaAMBEV - a maior cervejaria da América Latina, responsável pela produção das marcas: Antarctica, Brahma, Bohemia, Caracu, Kronenbier, Liber, Miller, Original, Polar, Serra Malte, Skol etc - a seguir, entrevistamos a publicitária responsável pelo atendimento de tal agência. Questionamos sobre a insistência da cervejaria em produzir campanhas comerciais que exploram 0 erotismo. Segundo a publicitária, as pesquisas de mercado revelam que a cerveja continua a ser vista como um "produto masculino", e, por isso, a imagem feminina continua a ser usada como um chamariz para a marca.

Quando indagada sobre as reações ou demandas do público-consumidor feminino, a publicitária afirmou que não há rejeição das campanhas por parte desse público, pelo contrário, afirmou haver uma forte identificação das mulheres com as garotas-propaganda. É claro que tal afirmativa deve ser ponderada numa análise sociológica da atividade publicitária, uma vez que pode ser observado na fala da publicitária uma equivalência, presente no senso-comum, entre sexogênero e desejo. 
Por ocasião da realização da dissertação de mestrado, tivemos a oportunidade de aprofundar os estudos sobre a publicidade brasileira. Dessa vez o foco da pesquisa passou a ser a mensagem. Durante um ano acompanhamos a programação de dois canais da televisão aberta, a Rede Globo e o SBT, em horários diversificados, e gravamos os intervalos comerciais. Após a coleta e seleção das peças que centram sua mensagem no corpo feminino pôde-se perceber a existência de um conjunto de representações da mulher ${ }^{2}$ que se repetem no anúncio de diferentes produtos. São elas: a "mãe", que zela pela casa e pelos filhos; a "mulher moderna", que concilia vida profissional e doméstica; a "patricinha", que se preocupa com a aparência; e, a "gostosona", que alia a preocupação com a beleza ao erotismo.

Depois de classificar todo o material coletado de acordo com os estereótipos mencionados acima, selecionamos as peças comerciais mais representativas de cada categoria a fim de realizar uma análise de conteúdo 3 . A opção por trabalhar com a mídia audiovisual deve-se a sua grande acessibilidade. Em primeiro lugar, porque, como mostra Ramos (1987), a linguagem audiovisual é instantânea e direta. 0 comercial de TV falando e mostrando, conduzindo em movimentos é gráfico e literal, sendo facilmente compreendido por todos os públicos. Em segundo lugar, porque, de acordo com o Censo 2000 realizado pelo $\mathrm{IBGE}^{4}$ nos municípios com até 20 mil habitantes, 74,2\% dos domicílios tinham televisão, e, nos municípios com mais de 500 mil habitantes, essa proporção chega a ser de 96\%. Isso significa que além da grande facilidade de compreensão, o comercial de TV também atinge um grande número de pessoas.

Buscando compreender os diferentes usos que a publicidade comercial faz da imagem feminina, entendendo principalmente a persistência de certas concepções tidas como tradicionais a respeito do que é "ser mulher", como,

\footnotetext{
${ }^{2}$ Aqui o termo representação está sendo compreendido, conforme propõe Therborn (1989), como a aceitação dos critérios dominantes como verdadeiros. De acordo com o autor, as representações atuam como um efeito de enunciação sobre o qual se determina o que é normal ou aconselhável e, por extensão, define-se o desviante ou anormal.

${ }^{3} \mathrm{~A}$ análise de conteúdo é uma metodologia de análise de textos que parte de uma perspectiva quantitativa e qualitativa. Por isso, analisa-se a frequência numérica de determinados termos, construções e referências, e, ainda tem como unidade de informação de base a presença ou ausência de uma característica, que, no caso, é a imagem feminina como elemento central da mensagem publicitária.

${ }^{4}$ Dados retirados do site <http://www.ibge.gov.br/home/presidencia/noticias/20122002censo. shtm>. Acesso em: 19/01/2010
} 
por exemplo, a maternidade. Esse trabalho teve que lançar mão não apenas das teorias da comunicação, como também dos estudos feministas. Nesse artigo, o tema é a contribuição dos estudos feministas para a teoria social. 0 objeto, que nos servirá para exemplificar tais contribuições, será a atividade publicitária; as peças televisionadas constituem nosso referencial empírico.

Partiremos da premissa de que a publicidade, ao veicular repetidamente as representações femininas mencionadas acima, contribui para a reprodução do status subalterno atribuído as mulheres nas sociedades ocidentais. Enquanto para o movimento feminista, que luta pela emancipação das formas de vida, a atividade publicitária se apresenta como o flanco adversário; para os estudos de gênero, ela vem reforçar o argumento de que vivemos numa sociedade generificada, na qual há uma divisão dos papéis de gênero.

A fim de compreendermos a opressão social de gênero de forma global, seguiremos as contribuições de Hollanda (1994) e Lauretis (1994), que ao operarem uma síntese entre os estudos clássicos, como a crítica à cultura, e os pósmodernos, que concebem o poder atuando de forma horizontal, lançam as bases para uma nova teorização acerca da opressão de gênero. Segundo as autoras, antes de serem perspectivas teóricas meramente excludentes, tais correntes analíticas devem ser tomadas como explicações complementares acerca da realidade social.

Seguindo a trilha deixada pelas autoras, iniciaremos esse artigo com um breve panorama acerca da trajetória do pensamento social que versam sobre 0 poder e a dominação. Partiremos das concepções analíticas dos estudos clássicos, representados pelas teorizações de Engels (1991) e Marx (1991;1996), passando, a seguir, de forma bastante rápida, pelos teóricos pós-modernos - entre os quais citamos Foucault (1984; 1988) e Hall (1992). Objetivamos, com isso, compreender como tais correntes analíticas, articuladas aos estudos de gênero, contribuíram para o desenvolvimento da teoria social.

É claro que uma mudança no foco de análise, da macrossociologia dos estudos clássicos para os fenômenos microssociológicos, alvo das preocupações dos pós-modernos, acarreta algumas incompatibilidades de comparação entre tais correntes. Não ignoramos tais riscos, contudo, visamos apenas demonstrar como alguns aspectos da teoria clássica foram superados, como, por exemplo, sua concepção de sujeito universal; na medida em que outros, como a perspectiva histórica e a concepção de sociedade enquanto uma totalidade integrada, foram retomados pelos estudos feministas. 


\section{Poder e Subjetividade: Permanências E SUPERAÇÕES NA TEORIA SOCIAL}

Para Marx (1996), a sociedade deve ser compreendida como uma unidade, uma totalidade composta pelos processos infra-estruturais - que abarcam os processos econômicos e as relações sociais de produção - e pelos fenômenos da superestrutura (que dizem respeito às produções da esfera cultural, tais como as ideologias, o direito, a filosofia, as concepções religiosas e científicas). Para o autor, uma verdadeira análise do mundo social não poderia prescindir de nenhuma dessas duas esferas, posto que há uma forte imbricação entre elas. Assim, a teoria social, para Marx (1996), deve primeiramente resgatar os processos históricos através dos quais tais esferas se constituíram, a fim de identificar as articulações existentes entre seus processos.

Para o autor, o modo de produção capitalista constitui-se num obstáculo específico à plena realização do bomem universal - conforme propunha 0 pensamento humanista - pois, na medida em que suprime a posse dos meios de produção dos trabalhadores, aliena-os e inaugura uma nova hierarquia social, polarizada entre proprietários e não-proprietários.

Como herdeiro do pensamento iluminista, Marx compreendia os indivíduos como sujeitos unificados, totalmente centrados, portadores de um eu interior que constituiria a sua identidade pessoal. Os sujeitos em Marx eram pensados no interior das estruturas, pois, segundo o autor, os homens produzem-se socialmente apenas por meio do trabalho, ou seja, sua existência social se daria apenas enquanto agentes transformadores da natureza.

De acordo com o autor, nos modos de produção anteriores ao capitalismo havia uma divisão natural do trabalho, que se orientava pelas diferenças de idade, força física e sexo. Com o surgimento do excedente e a expropriação dos meios de produção, no contexto capitalista, estabelece-se a divisão social do trabalho.

Nascia, portanto, segundo Marx, uma nova forma de organização social, centrada na oposição entre burgueses e proletários. Essa divisão em classe, segundo 0 autor, garantiria a alguns indivíduos um acesso privilegiado na distribuição dos meios de produção e dos frutos do trabalho, assegurando a esses ainda o domínio na exploração dos grupos menos favorecidos. Dessa forma, a opressão social, para Marx (1996), deveria ser compreendida como sendo exercida primordialmente ao nível de classe. 
A grande crítica feita a essa perspectiva metodológica reside no fato do autor pensar a opressão social como sendo exercida apenas no interior das estruturas sociais, deixando de abordá-la em outras clivagens sociais, como, por exemplo, a opressão de gênero, raça e sexualidade. Tal abordagem pode ser justificada, em primeiro lugar, pela ausência das chamadas ciências auxiliares, que atualmente contribuem para a análise do cenário social, e, em segundo lugar, pela concepção de sujeito que informava o autor. De acordo com Lauretis (1994), faltava em Marx uma teoria da subjetividade, que seria pensada mais tarde pelos chamados teóricos pós-modernos.

Entre esses, podemos citar Foucault (1984; 1988) e Hall (1992), os quais afirmam que as sociedades modernas são marcadas por fortes mudanças estruturais e institucionais derivadas da consolidação do processo de globalização. Nesse contexto, o sujeito anteriormente entendido como portador de identidade interior, única e estável torna-se mutável e relacional devido à fragmentação das paisagens culturais de classe, gênero, sexualidade, etnia, raça e nacionalidade. Portanto, as identidades pessoais (ou seja, a ideia que temos de nós próprios como sujeitos), segundo Hall (1992), tornaram-se múltiplas e cambiantes, construídas em meio aos processos discursivos.

Destarte, a concepção pós-moderna de sujeito afirma que as identidades individuais são construções fluidas e móveis, que não se limitam às relações sociais de produção, como concebia a concepção clássica; antes, são formadas pela interação entre estruturas discursivas que são simultaneamente políticas e culturais, como, por exemplo, os sistemas simbólicos da arte, da língua, da religião etc. Nessa perspectiva, as identidades individuais deixam de ser determinadas pela essência do ser, para serem concebidas como algo relacional, fruto dos processos de identificação/diferenciação.

É, portanto, nesse cenário de consolidação de novos paradigmas, que os estudos feministas ganharam notoriedade. Segundo Hollanda (1994), a crítica feminista começa evidenciar-se no cenário social e político entre as décadas de 1960 e 1970, quando juntamente com os movimentos anticoloniais, étnicos, raciais, ecológicos e homossexuais trazem para o debate a questão da alteridade e do lugar da diferença. Preocupadas em admitir uma verdadeira identidade feminina, as teóricas dessa época cunham o conceito de gênero, que inicialmente referia-se a transformação da diferença anatômica dos sexos em elemento legitimador de uma ordem social misógina. 
A partir de tal premissa, as práticas sociais e os discursos passaram a ser entendidos como mecanismos de poder, estratégias que criam espaços sociais gendrados, ${ }^{5}$ que visam manter inalterados os pressupostos da dominação masculina ${ }^{6}$.

Um segundo momento do movimento feminista, de acordo com Lauretis (1994), foi fortemente influenciado pela teoria da sexualidade de Foucault (1984, p. 244), a partir da qual passou-se a contestar a concepção de gênero fundamentada na diferença sexual. Para o autor, a sexualidade deve ser entendida como um dispositivo de poder, "um conjunto decididamente heterogêneo que engloba discursos, instituições, organizações arquitetônicas, decisões regulamentares, leis, medidas administrativas, enunciados científicos, proposições filosóficas, morais e filantrópicas". Da mesma forma, como a sexualidade não poderia mais ser concebida como um atributo natural dos corpos, posto que não existe a priori nos seres humanos, o conceito de gênero deveria deixar de ser informado pelas características sexuais.

As concepções correntes sobre a sexualidade feminina e masculina, segundo Foucault, seriam estratégias discursivas, que visam anular as semelhanças existentes entre homens e mulheres e tornar compulsória as performances de gênero ${ }^{7}$. Espera-se que os homens tenham corpos musculosos; que sejam símbolos de força e de virilidade, que a masculinidade seja sinônimo de coragem, auto-controle e agressividade. Das mulheres, esperam-se formas físicas menos rígidas e mais curvilíneas. A feminilidade passa a ser definida pelo altruísmo da maternidade, pela docilidade de seus comportamentos, pela fragilidade e pela submissão, primeiramente ao pai, posteriormente, ao marido. Contemporaneamente, segundo mostra Priori (2000), ocorre uma submissão feminina aos ideais de beleza tão propagados pela mídia.

Para Foucault (1988), opoder seria constitutivo do próprio desejo, ou seja, há, segundo o autor, uma estreita correlação entre nossos desejos e o que sabemos

\footnotetext{
${ }^{5} 0$ termo Gendrado é usado por Lauretis (1994, p. 212) para designar espaços "marcados por especifidades de gênero".

${ }^{6}$ Em Bourdieu (2002) dominação masculina se refere à supremacia de uma visão de mundo patriarcal e falocêntrica.

${ }^{7}$ Butler (2003) utiliza performances de gênero para se referir a uma identidade de gênero que é forjada por meio de ações, signos corporais e outros meios discursivos, e é mantida com o propósito de regular a sexualidade dentro do marco obrigatório da heterossexualidade reprodutiva.
} 
sobre o nosso sexo; haveria, portanto, uma correspondência entre poder e saber. Desse modo, fica claro o motivo pelo qual o discurso dominante, que visa manter intacta a hegemonia masculina, tomou as características anatômicas do sexo masculino como elemento estruturante da hierarquia social.

No entanto, conforme aponta Lauretis (1994), a perspectiva de Foucault que pensa o gênero como produto e processo de um certo número de tecnologias sociais, de aparatos médicos e biológicos, acaba sendo incompatível com a concepção de gênero baseada na diferença sexual. A perspectiva foucaultiana seria insuficiente para os estudos de gênero, uma vez que o autor não levou em consideração os apelos diferenciados dos dispositivos de poder aos sujeitos masculinos e femininos. Segundo Lauretis (1994), a equiparar poder e conhecimento, Foucault (1984) entende o poder como produtor de significados, valores, conhecimentos e práticas, mas, não consegue explicar como as pessoas se constituem como resultado do fato de certas verdades e não de outras.

De acordo com Fernández (2000), a relação do feminismo com Foucault é uma relação ambígua e tensa, posto que, na medida em que o autor contribuiu para a compreensão da sexualidade e das identidades como construções discursivas, de caráter ficcional, ele dissolveu simultaneamente as bases normativas que permitiam ao feminismo projetar políticas sexuais que contribuiriam para 0 desenvolvimento de formas de vida emancipadas.

Uma alternativa à essa tensão entre desconstrução e reconstrução dos significados pode ser encontrada em Bourdieu (2002). Para o autor, a dominação masculina vem se perpetuando pela ação de estruturas subjetivas, como a aquisição do habitus de gênero ${ }^{8}$, atreladas à ação de estruturas objetivas, por meio dos processos de socialização oriundos de instituições como a Igreja, a Escola, a Família, e, mais modernamente, a Mídia.

Criticando Bourdieu (2002), Mariza Corrêa (1999, p.10) afirma que a dominação masculina não é tão homogênea ou hegemônica como apresentado pelo autor, uma vez que "o princípio da dominação em qualquer sociedade é acessível, em princípio, a ‘homens' e 'mulheres' - se for socialmente necessário,

\footnotetext{
${ }^{8} 0$ conceito habitus, segundo Bourdieu (2007), diz respeito a um aprendizado passado, uma espécie de modus operandi, que, através da repetição, opera como uma disposição estável para se agir em determinada direção, tornando-se uma espécie de segunda natureza bumana. 0 habitus seria, portanto, um conhecimento adquirido através da interiorização de valores, normas e princípios sociais que tende a orientar a escolha dos indivíduos.
} 
politicamente desejável e economicamente "rentável'". Nesse sentido, tanto homens como mulheres podem ocupar o lugar da dominação.

0 interessante da obra de Bourdieu, segundo Corrêa (1999), é sua percepção do lento trabalho dos processos de socialização que estruturam a percepção sobre os órgãos sexuais, isto é, a aquisição de diferentes habitus que constroem o que é ser mulher e o que é ser homem nas sociedades ocidentais. É importante também, sua percepção de como a lógica sexuada da dominação constrói corpos, e, consequentemente, subjetividades masculinas e femininas. Pois, conforme afirma Corrêa (1999), antes de serem resultado de verdades anatômicas dos corpos, os princípios masculinos e femininos são normas estruturais e estruturantes, que circulam tanto na sociedade cabila - estudada por Bourdieu - como nas sociedades ocidentais contemporâneas.

Uma vez que a transformação cultural do sexo em gênero constitui uma das mais importantes expressões contemporâneas da desigualdade social, algumas teóricas feministas, como Lauretis (1994) e Hollanda (1994), passaram a buscar uma articulação entre os estudos clássicos e as concepções modernas de sujeito e de identidade, a fim de suprirem algumas lacunas analíticas, conforme veremos a seguir.

\section{O RESGATE DO CONCEITO DE IDEOLOGIA E A TRANSFORMAÇÃO DA TEORIA FEMINISTA EM CRÍTICA DA CULTURA}

Durante muito tempo a categoria Mulher foi usada para representar uma essência feminina, concebida como estando próxima da Natureza, coberta por mistérios, como por exemplo, sua proximidade com o mal, herança do pecado original cometido por Eva ao comer a maçã. Foi representada também como madona, anjo ou demônio.

A categoria mulher referir-se-ia a um sujeito universal que, segundo Lauretis (1994), tornava quase imperceptível as diferenças existentes entre as próprias mulheres, entre brancas e negras, brancas ricas e brancas pobres, negras ricas e negras pobres, entre lésbicas, bissexuais e heterossexuais.

Essa ideia acerca de uma identidade feminina estável e unívoca passou a ser contestada a partir das concepções de sujeito e de identidade oriundas dos estudos pós-modernos. Conforme vimos, foi a partir da teoria da sexualidade de 
Foucault (1988), que o movimento feminista das décadas de 1970 e 1980, passou a conceber Gênero como uma representação social. De tal forma que o sujeito e a subjetividade, segundo Lauretis (1994, p. 208), passaram a ser entendidos em sua relação com a sociabilidade, ou seja:

[como] um sujeito constituído no gênero, sem dúvida, mas não apenas pela diferença sexual, e sim por meio de códigos linguísticos e representações culturais; um sujeito "engendrado" não só na experiência de relações de sexo, mas também nas de raça e classe: um sujeito, portanto, múltiplo em vez de único, e contraditório em vez de simplesmente dividido

0 conceito de Gênero passaria então a se referir a um conjunto de relações sociais pré-determinadas para cada sexo. A uma relação de pertencimento a um determinado grupo e a posição atribuída a esse grupo na hierarquia social. Vale ressaltar que Gênero não é sexo, nem uma condição natural dos corpos. Antes, Gênero equivale a uma representação hegemônica que opõem os dois sexos biológicos e estabelece uma relação hierárquica entre eles, que os estudos de gênero, como o de Rubin (1975), denominaram de sistema sexo-gêner0 sistema sexo-gênero, de acordo com Lauretis (1994, p. 211), pode ser definido como:

duas categorias complementares [masculino e feminino], mas que se excluem mutuamente, nas quais todos os seres humanos são classificados formam [sic], dentro de cada cultura, um sistema de gênero, um sistema simbólico ou um sistema de significações que relaciona o sexo a conteúdos culturais de acordo com valores e hierarquias sexuais. Embora os significados possam variar de uma cultura para outra, qualquer sistema sexo-gênero está sempre intimamente interligado a fatores políticos e econômicos de cada sociedade.

Ao produzir peças comerciais, ora destinadas ao público masculino, ora direcionadas ao público feminino, a publicidade cumpre papel fundamental na manutenção da ideologia dominante. Como um instrumento dessa representação hegemônica, que prescreve uma oposição binária e complementar entre os gêneros, a publicidade atua como um dos mecanismos ideológicos que legitima e reproduz a ordem social androcêntrica.

Mas, que não se escandalizem os teóricos dos cultural studies, pois, a concepção de ideologia empregada nesse artigo não se resume à definição da corrente marxista clássica que a concebe como um conjunto sistemático de "ideias falsas" derivadas dos processos econômicos. Adotamos o conceito de ideologia como uma forma de discurso, que interpela e qualifica os sujeitos e 
suas identidades sociais. Apesar de ser uma abordagem alternativa à concepção clássica, o termo, nesse sentido, preserva, ao menos em parte, o significado de falsa consciência, uma vez que o discurso de gênero representa relações imaginárias e não reais, que governam a existência dos indivíduos.

Tal acepção encontra suas bases nas contribuições de Gramsci (2000). Para 0 autor, as sociedades modernas são constituídas por diversos grupos, classes e fragmentos de classe que permanecem em constante disputa para impor sua visão de mundo. Assim, um grupo se torna hegemônico quando sua ideologia - ou, nas palavras do autor, sua visão de mundo - passa a ser estendida a toda sociedade. Logo, a ideologia dominante consiste na hegemonia da visão de mundo do grupo dominante, ou seja, na capacidade de um grupo de estender sua esfera de liderança e de autoridade sobre toda a sociedade.

Contudo, segundo Gramsci (2000), a imposição de uma visão de mundo não se dá por meio da força, efetiva-se mediante uma aliança de consentimento entre dominantes e dominados. Nesse sentido, a dominação masculina, cujo sujeito é o homem, burguês, branco e heterossexual, não deve ser entendida unicamente por meio da ameaça da violência física, e sim, conforme Bourdieu (2007), como uma forma de violência simbólica, exercida por meio da aceitação e adesão das mulheres. A aquiescência feminina, segundo o autor, deve-se à interiorização dos esquemas pensamento (o babitus) do grupo dominante a respeito do próprio corpo e de suas capacidades intelectuais e profissionais.

Desse modo, a exploração e mercantilização do corpo feminino pela publicidade, assim como o uso reincidente de estereótipos que reforçam o lugar subalterno atribuído às mulheres nas sociedades modernas, aparece a elas como algo natural. Apresentaremos, a seguir, dois exemplos de peças publicitárias, com 0 propósito de demonstrar como a publicidade opera de forma engenhosa e sutil na manutenção da ideologia dominante. A primeira é dirigida ao público masculino e a segunda ao público feminino.

\section{A IDEOLOGIA DE GÊNERO NA PUBLICIDADE}

Conforme vimos acima, há no mínimo cinco representações ou estereótipos femininos usados pela atividade publicitária contemporânea. Contudo, em função dos limites estipulados para um artigo apresentaremos, a seguir, apenas dois exemplos de peças comerciais que corroboram com os estudos feministas. 
A primeira campanha é intitulada "A fábrica da Kaiser" e é dirigida ao público-consumidor masculino. A segunda tem como título "Mabe: a marca da multimulher" e dirige-se sobretudo ao público feminino. A primeira delas faz uso da analogia entre mulher e cerveja, apelando para a esfera erótica. A campanha é representada pela sequência de fotos a seguir.

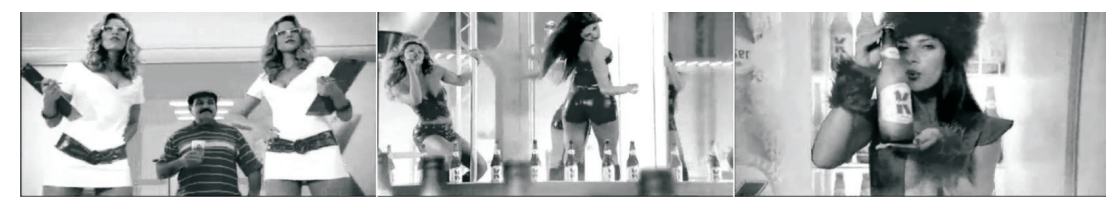

Nesse filme publicitário, o garoto propaganda da marca - popularmente conhecido como "O Baixinho" - aparece acompanhado de duas mulheres loiras. Elas estão vestidas com roupa formal, porém bem curtas e decotadas, carregam pranchetas onde anotam os pontos inspecionados na fábrica da Kaiser. 0 ambiente é futurista e todos os funcionários dessa fábrica são mulheres, que trabalham em trajes sensuais. Em seguida, a locução lança a seguinte questão: "Sabe por que a Kaiser é mais que gostosa?", e prossegue apresentando todos os elementos que ressaltariam a qualidade da cerveja, como a cevada, a água e o controle de qualidade. Cada um desses elementos está associado à figura de uma ou mais mulheres. A cena seguinte simula a fase do engarrafamento. Com uma música sensual de fundo um grupo de mulheres dança sensualmente em barra de ferros verticais, e, enquanto uma das modelos beija a tapa da garrafa e ao fechá-la a locução completa: "Tudo isso pra você!" Depois de engarrafadas - mulher e cerveja - são lançadas diretamente para o refrigerador de um bar, quando o garoto propaganda da marca aperta um botão. Por fim, a última cena retrata um bar onde o garçom ao abrir a porta do refrigerador recebe das mãos de uma das supostas funcionárias da fábrica da Kaiser uma cerveja, conforme mostra a terceira imagem. 0 filme acaba com o garçom dizendo: "Isso é que é tecnologia!"

Uma análise menos atenta dessa mensagem poderia afirmar que a campanha publicitária quis transmitir ao seu público-alvo o tratamento "todo especial" que a cervejaria tem para com seus produtos, o cuidado e a preocupação da Kaiser em produzir o melhor para seus consumidores. Todavia, uma análise sociológica dessa peça revela que o uso da imagem feminina agrega ainda outros sentidos à mensagem. A associação da figura feminina ao produto, que 
aparentemente serviria apenas como um apelo para que o público-alvo consuma a cerveja, revela-se, em sua essência, um recurso eficaz de afirmação de um status que reserva à mulher o papel de objeto do prazer, de coadjuvante e não de sujeito.

Ao dirigir sua mensagem ao público masculino, a publicidade está reforçando os pressupostos da heterossexualidade compulsória ${ }^{9}$, na qual há uma oposição binária e complementar entre sexo-gênero e desejo. Revela-se, dessa forma, sua função ideológica. Mas, como ficaria o público feminino consumidor de cerveja?

Após notar a insuficiência de outras formas de análise, pudemos perceber que as mensagens publicitárias são polissêmicas, isto é, permeadas por simbologias e pela justaposição de ideias que as dotam de sentidos ambíguos, a fim de dissuadir possíveis incoerências na interpretação da mensagem. As consumidoras são retratadas como objeto de desejo, contudo, são dotadas de uma capacidade de mobilizar o desejo masculino. Essa ambiguidade se coaduna ainda com a interiorização dos supostos do dominador pelo dominado. Faz com que a violência contra a mulher, presente nesse tipo de campanha, seja quase completamente ocultada, ou seja, opera como uma forma de violência simbólica que se camufla na naturalização dos papéis sociais.

0 uso de diferentes clichês femininos tem por objetivo divulgar um produto que satisfaça as "necessidades" dos mais diferentes públicos. Na medida em que as mulheres passaram a se constituir em importantes mercados consumidores, novos clichês foram mobilizados.

0 segundo exemplo de campanha comercial selecionada para esse artigo refere-se a esse aspecto: a mulhercomo público-alvo. Uma linha de eletrodomésticos resolveu comunicar-se com a "mulher-moderna", ou seja, aquela que participa do mercado de trabalho, mas não deixa de lado os cuidados com a casa, com 0 marido e com os filhos. Veja a descrição-análise da peça a seguir:

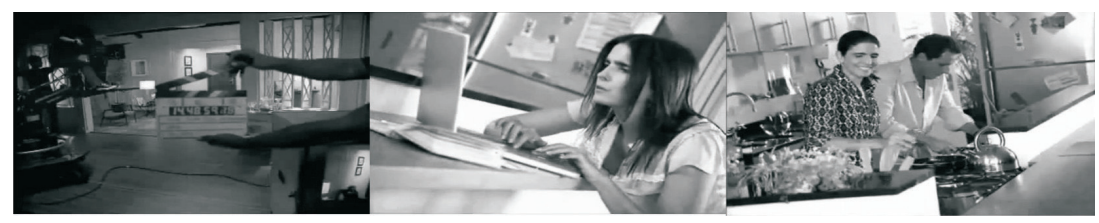

A propaganda começa mostrando uma outra atuação da atriz Malu Mader. A primeira imagem, de uma claquete, marca o início do expediente de trabalho para

${ }^{9}$ Conceito presente na obra de Judith Butler (2003). 
a atriz. Já nos bastidores do cenário, ela afirma: "Tem vários papéis que interpreto que nem todos vêem ou aplaudem". A seguir, uma sequência de imagens da atriz em sua residência equipada com os eletrodomésticos da marca representam seus afazeres domésticos. A mensagem que a campanha pretende transmitir é que além da vida profissional, a personagem não se exime de suas obrigações "de mulher". As imagens em que ela aparece desempenhando suas atividades cotidianas, como acordar os filhos, fazer contas no computador, cozinhar, se maquiar, arrumar flores em um vaso, vestir os óculos de sol no esposo no momento em que esse se despede, são acompanhadas pela narração: "De manhã, sou especialista em recursos humanos. Aí faço papel de $\mathrm{PhD}$ em economia. Viro chefe de cozinha, maquiadora, decoradora e até produtora de moda, eu tenho que ser". Novamente volta-se ao set de filmagem, e ela encerra sua narração sorrindo e dizendo: "Papéis que tenho orgulho em desempenhar: a multimulher." Enquanto mostra a coleção de eletrodomésticos da marca, o comercial termina com uma segunda narradora dizendo: "Chegou a linha de eletrodomésticos que vai descomplicar sua vida. Mabe: a marca da multimulher".

0 termo multimulher empregado no anúncio sugere um acúmulo de tarefas para a mulher moderna. Por mais que essas tenham conquistado seu espaço no mercado de trabalho, elas não se emanciparam de suas obrigações domésticas, tendo que se desdobrarem para cumprirem com êxito as duas jornadas de trabalho. E, para auxiliá-las nessa dupla jornada, nada melhor do que seus velhos companheiros: os eletrodomésticos.

Apesar de já haver outros tipos de campanhas comerciais que fogem desse padrão hegemônico (que visam atender as especifidades dos grupos subalternos, que têm despontado como importantes nichos de mercado), nota-se que ainda há o predomínio da Ideologia de Gênero na atividade publicitária contemporânea. Logo, a forma como homens e mulheres vivem sua subjetividade, constroem sua identidade e tecem suas relações sociais não resultam apenas de sua trajetória individual, derivam também de um conjunto de interpelações ideológicas, das quais a atividade publicitária foi um exemplo.

\section{Conclusão}

Vimos que, num primeiro momento, os estudos feministas lançavam mão do conceito de gênero como uma categoria analítica baseada na diferença sexual. Tal concepção, segundo Hollanda (1994), orientou a busca pela verdadeira 
identidade feminina e pelo lugar da diferença na ordem social contemporânea. Contudo, de acordo com Lauretis (1994), o conceito de gênero nessa acepção acabou por se tornar uma limitação ao pensamento feminista. Pois, uma vez que o foco da análise se volta para as características sexuais, o pensamento passa a ser confinado a uma oposição universal do sexo, engessando, desse modo, os sujeitos numa dicotomia de essências arquetípicas, que não correspondem às realidades cambiantes e flexíveis de se viver a sexualidade.

Foi, portanto, a partir das contribuições de Foucault (1988) que o conceito de gênero deixou de se remeter à diferença sexual e passou a ser entendido como uma representação social, ou, como coloca Lauretis (1994), uma tecnologia social, que tem por função definir o lugar e o papel destinado a cada indivíduo na ordem social. Nesse sentido, o gênero, é o responsável por transformar os indivíduos em sujeitos masculinos ou femininos. É nesse aspecto que Lauretis (1994, p. 213) aproxima-se da concepção marxista de Ideologia, a a afirmar que as relações de Gênero "não representam o sistema de relações reais que governam a existência dos indivíduos e sim a relação imaginária daqueles indivíduos com as relações reais em que vivem".

Uma análise sociológica da atividade publicitária revelou que, mais do que uma técnica de comunicação isenta de qualquer valor, a publicidade é um importante mecanismo ideológico. Como um dos espaços através dos quais se dão os processos de socialização secundários, a publicidade reproduz os padrões hegemônicos, prescrevendo normas de comportamento e regras de conduta, tidos como masculinos ou femininos. Ao sugerir modelos de feminilidade que estão associados à existência ou não de certos atributos considerados como inatos ou naturalizados, como, por exemplo, o apelo à sensualidade feminina, a publicidade está contribuindo para reprodução do status subalterno atribuído às mulheres.

A análise sobre os usos da imagem feminina em campanhas publicitárias, que esboçamos aqui, mostrou que a teoria feminista legou importantes contribuições para a teoria social, ajudando a preencher as lacunas deixadas pelas escolas estruturalistas ou fenomenológicas, na análise da opressão de gênero. 


\section{REFERÊNCIAS}

BELELI, Iara. Marcas da diferença da propaganda brasileira. Tese de Doutorado, Ciências Sociais, Instituto de Filosofia e Ciências Humanas, Universidade Estadual de Campinas, 2005.

BUTLER, Judith. Problemas de gênero: feminismo e subversão da identidade. Rio de Janeiro: Editora Civilização. Brasileira, 2003.

BOURDIEU, Pierre. O poder simbólico. Rio de Janeiro: Bertrand do Brasil, 2007. . A dominação masculina. Rio de Janeiro: Bertrand do Brasil, 2002.

CORRÊA, Mariza. 0 sexo da dominação. Novos Estudos CEBRAP, n. 54, São Paulo, 1999.

DEL PRIORI, Mary. Corpo a corpo com a mulher: pequena história das transformaç̃̃es do corpo feminino no Brasil. São Paulo: Editora Senac, 2000.

ENGELS, Frederic; MARX, Karl Heinrich. A ideologia alemã e outros escritos. São Paulo: Hucitec, 1991.

ESCOSTEGUY, Ana Carolina; MESSA, Márcia Rejane. Os estudos de gênero na pesquisa em comunicação no Brasil. Contemporânea, Revista de Comunicação e Cultura. Porto Alegre, vol.4, n. 2, 2006.

FERNÁNDEZ, Josefina. Foucault: ¿Marido o Amante? Algunas tensiones entre Foucault y el feminismo. Revista de Estudos Feministas, n. 2, Florianópolis, 2000.

FOUCAULT, Michel. História da sexualidade I: a vontade de saber. Rio de Janeiro: Graal, 1988.

. Por uma Genealogia do Poder. In: Microfísica do poder. vol. 7. Rio de Janeiro: Graal, 1984.

GRAMSCI, Antonio. Caderno 12: apontamentos e notas dispersas para um grupo de ensaios sobre a história dos intelectuais. In: Cadernos do Cárcere. vol. 2. Rio de Janeiro: Civilização Brasileira, 2000.

HALL, Stuart. A identidade cultural na pós-modernidade. Rio de Janeiro: DP\&A, 1992. 
HOLLANDA, Heloísa Buarque de. Feminismo em tempos pós-modernos. In: HOLLANDA, Heloísa Buarque de. (org.). Tendências e Impasses - 0 feminismo como crítica da cultura. Rio de Janeiro: Rocco, 1994.

LAURETIS, Teresa de. A tecnologia de Gênero. In: HOLLANDA, Heloísa Buarque de. (org.). Tendências e Impasses - 0 feminismo como crítica da cultura. Rio de Janeiro: Rocco, 1994.

MARX, Karl. Mercadoria e dinheiro In: O capital: crítica da economia política. vol. 1. São Paulo: Nova Cultural, 1996.

RAMOS, Ricardo. Contato imediato com a propaganda. São Paulo: Editora Global, 1987.

RUBIN, Gayle. The Traffic in Women. Notes on the "Political Economy" of Sex. In: REITER, Rayna (ed.) Toward an Anthropology of Women. New York: Monthly Review Press, 1975.

THERBORN, Göran. La ideología del poder y el poder de la ideología. México: Siglo XXI, 1989. 